\title{
DIREITOS DA NATUREZA E ACESSO À JUSTIÇA: A Ampliação dos Atores Legitimados em Ações Coletivas Para uma Justiça Socioambiental
}

\author{
http://dx.doi.org/10.21527/2176-6622.2020.54.118-131
}

Recebido em: 7/9/2020

Aceito em: 19/9/2020

Márcia Rodrigues Bertoldi

Doutora em Direito pela Universitat de Girona. Professora na Faculdade de Direito e no Programa de Pós-Graduação em Direito. Coordenadora do Programa de Pós-Graduação em Direito da Universidade Federal de Pelotas/RS. http://lattes.cnpq.br/2979973414270206. https://orcid.org/0000-0003-3161-0445. marciabertoldi@yahoo.com

\section{Roberta Fortunato Silva}

Mestranda no Programa de Pós-Graduação em Direito da Universidade Federal de Pelotas/RS. Especialista em Direito Público pela Faculdade Damásio/SP. Especialista em Direito Ambiental pelo Centro Universitário Internacional Uninter/PR. Bacharela em Direito. http://lattes.cnpq.br/0313353427502475. https://orcid.org/00000002-8401-4383.roberta_rfs@yahoo.com.br

\section{RESUMO}

O presente estudo defende a superação das amarras existentes no âmbito processual, propondo o alargamento do rol de sujeitos que podem iniciar a busca por proteção judicial em defesa do meio ambiente para o cumprimento dos direitos da natureza. $O$ direito de acesso à justiça deve ser amplamente assegurado pelos instrumentos processuais de um ordenamento jurídico, notadamente em se tratando de demandas coletivas. Assim, estuda-se a trajetória do pensamento humano sobre a natureza para compreender os paradigmas da ética ambiental que legitimam os direitos da natureza; os direitos da natureza, os quais incluem o reconhecimento da natureza como sujeito de direitos; e a necessidade de alargamento do rol de sujeitos legitimados, especificamente em Ação Civil Pública ambiental, para o acesso à justiça dos direitos da natureza e para a execução da justiça socioambiental. Conclui-se que o alargamento deste rol é uma oportuna estratégia para promover um acesso à justiça mais amplo e efetivo para os direitos da natureza e, como efeito, a justiça socioambiental. Utilizou-se, nesta pesquisa, o método dedutivo, revisando bibliografia e documentos como procedimento.

Palavras-chave: Acesso à justiça. Direitos da natureza. Paradigma ecocêntrico. Proteção ambiental. Justiça socioambiental.

\section{DERECHOS DE LA NATURALEZA Y ACCESO A LA JUSTICIA: \\ LA AMPLIACIÓN DE LOS ATORES LEGITIMADOS EN ACCIONES COLECTIVAS PARA UMA JUSTICIA SOCIOAMBIENTAL}

\section{RESUMEN}

El estudio sostiene la superación de los obstáculos en el ámbito del proceso y propone la ampliación del rol de sujetos capaces para buscar protección judicial en la defensa del medio ambiente para el cumplimiento de los derechos de la naturaleza. El derecho de acceso a la justicia debe ser asegurado pelos instrumentos procesuales de un ordenamiento jurídico, especialmente en los casos de demandas colectivas. Así es que se estudia la trayectoria del pensamiento sobre la naturaleza para comprender los paradigmas de la ética ambiental que legitiman los derechos de la naturaleza; los derechos de la naturaleza, que incluyen el reconocimiento de la naturaleza como sujeto de derecho; y la necesidad de ampliación del rol de sujetos legitimados, específicamente en Acción Civil Pública ambiental, para el acceso a los derechos de la naturaleza a la justicia y para la ejecución de la justicia socioambiental. Se concluye que la ampliación del rol es una oportuna estrategia para promover un acceso a la justicia más amplio y efectivo para los derechos de la naturaleza y, en consecuencia, la justicia socioambiental. La investigación utiliza el método deductivo y revisa bibliografía y documentos.

Palabras-clave: Acceso a la justicia. Derechos de la naturaleza. Paradigma ecocéntrico. Protección ambiental. Justicia socioambiental.

\section{SUMÁRIO}

1 Introdução. 2 A trajetória do pensamento sobre a natureza para legitimar os direitos da natureza. 3 Direitos da natureza: a natureza como sujeito do/no direito. 4 Considerações sobre o alargamento do rol dos sujeitos de direito para o acesso à justiça e à justiça socioambiental. 4.1 As ondas renovatórias para o acesso à justiça. 4.2 Os sujeitos de direito no ordenamento jurídico brasileiro. 4.3. Ação Civil Pública e necessárias reformas. 5 Conclusão. 6 Referências. 


\section{INTRODUÇÃO}

A Constituição Federal de 1988 é um importante marco na proteção do meio ambiente e destaca tal proteção em capítulo específico dentro do Título da Ordem Social (BRASIL, 1988). Além disso, por meio da Emenda Constitucional n. 42/2003 (BRASIL, 2003), a tutela ambiental tornou-se princípio a ser observado no regime de pesos e contrapesos da ordem econômica e financeira.

Para além da construção constitucional em prol do meio ambiente, no entanto, é preciso garantir mecanismos processuais efetivos de proteção, tanto no aspecto preventivo quanto no repressivo, que sejam exitosos na antecipação dos danos, sobretudo porque irreversíveis na maior parte dos casos e na reparação dos prejuízos identificados na exata proporção do dano.

Tal qual preconizado por Mauro Cappelletti e Bryant Garth (1988, p. 12), a mera proclamação de direitos de nada serve sem que, para a sua efetivação, sejam garantidos mecanismos de reinvindicação, razão da importância do acesso à justiça como o mais básico dos direitos humanos. No Brasil, a Constituição Federal e a legislação infraconstitucional oferecem rituais que contemplam a proteção do meio ambiente, a exemplo da Ação Civil Pública, da Ação Popular e do Mandado de Segurança Coletivo.

Tais institutos processuais, contudo, ainda se mostram comprometidos com uma lógica privatística do direito e do processo civil, então compatível com o dogma liberal dos séculos 18 e 19, pautado no individualismo e no direito de propriedade. Nessa linha, apesar do aspecto difuso do meio ambiente, os mecanismos processuais existentes no Brasil ainda apresentam obstáculos que comprometem a efetividade do acesso à justiça para reparar ou reprimir danos ao meio ambiente que afetem os direitos da natureza e a consequente justiça socioambiental, a exemplo do problema da legitimidade e da representatividade, encontrados no rol de sujeitos processuais demasiadamente restritivo e limitado.

Nesse cenário, este artigo pretende pautar reflexões em uma concepção contemporânea de meio ambiente e, a partir da relevância dessa compreensão, defender a superação das amarras ainda existentes no âmbito do processual, propondo o alargamento do rol de sujeitos processuais que, com autonomia, podem iniciar a proteção judicial, a fim de assegurar o alcance de resultados que permitam dar ampla efetividade ao desiderato constitucional e infraconstitucional de defesa do meio ambiente para o cumprimento dos direitos da natureza e da justiça socioambiental.

Quanto à compreensão da natureza e a visão de sua essencialidade, o pensamento humano logrou mudanças ao longo dos séculos. Assim, entende-se necessário analisar esse desenvolvimento para se compreender os caminhos da salvaguarda jurídica dos direitos da natureza. É o que se estuda primeiramente.

O reconhecimento dos direitos da natureza, entre eles pertencer ao grupo dos sujeitos de direito, remonta ao pensamento ecocentrista, adotado em alguns países na América-Latina, na Austrália e na Nova Zelândia, por exemplo. Não está o Brasil, no entanto, incluído nesse núcleo, apesar de algumas demandas judiciais ajuizadas por elementos da natureza, de projeto de lei e decisão em sede do Supremo Tribunal Federal. Com o título Direitos da natureza: a natureza como sujeito do/no Direito, o item 3 aborda os direitos da natureza e a viabilidade do reconhecimento da natureza como um sujeito de direitos em uma proposta de ampliação do acesso à justiça ante a justiça socioambiental.

Entre outras, a lei tem a função de controle das resoluções de conflitos, com o propósito de uma aplicação justa, desvinculada de valores éticos, morais e religiosos. Com o intuito de organizar tais demandas, foram criados instrumentos e procedimentos para a sua apreciação pelos órgãos julgadores. Ou seja, foram instituídas normas para o acesso à justiça.

Não obstante, as problemáticas enfrentadas pela sociedade contemporânea tornaram-se mais complexas, exigindo o aprimoramento dos procedimentos processuais de salvaguarda dos direitos individuais, coletivos e difusos. Assim, o item 4 trata do acesso à justiça e das necessárias atualizações na lei processual capazes de enfrentar as dificuldades na proteção ambiental, no cumprimento dos direitos da natureza e na práxis da justiça socioambiental.

Com base nos conceitos de acesso à justiça e de direitos da natureza, parte-se da premissa maior de que a proteção do meio ambiente em prol dos direitos da natureza impõe instrumentos processuais hábeis para efetivá-los, aptos para acessar a justiça sem barreiras, e da premissa menor de que a Ação Civil Pública, instrumento mais utilizado em matéria ambiental, limita esse acesso por apresentar um rol taxativo de legitimados, 
bem como dificulta a justiça socioambiental. Desse modo, tem-se por conclusão que a proposta de alargamento do rol de legitimados desse instrumento, além da aptidão para considerar a natureza como sujeito de direitos, mostra-se como uma estratégia capaz de dar amplitude e efetividade à proteção ambiental para os direitos da natureza e na justiça socioambiental pela via do acesso à justiça. Por procedimento, revisaram-se as bibliografias especializadas nas temáticas bem como documentos relacionados.

\section{A TRAJETÓRIA DO PENSAMENTO SOBRE A NATUREZA PARA LEGITIMAR OS DIREITOS DA NATUREZA}

A compreensão da humanidade sobre a natureza logrou transformações no decorrer dos séculos, que refletiu na gerência do modelo de desenvolvimento escolhido pela sociedade internacional. Transcendeu-se o entendimento de que a natureza frui de imutalidade quando se reconheceu a finitude dos recursos naturais e a necessidade de salvaguarda para a manutenção da vida no planeta para as presentes e futuras gerações. Esta compreensão foi fundamental na construção do direito ambiental e dos direitos da natureza. ${ }^{1}$

$\mathrm{Na}$ Idade Antiga, entendia-se que as leis universais regiam a natureza, sendo o Universo reputado como ordenado e imutável e estando inserido na natureza (Cosmos) como um todo (GOMES, 2013, p. 31). Assim, a natureza constituía o mundo em sua totalidade, "incluindo o homem, a natureza não-humana e o sobrenatural", não havendo distinção clara entre o mundo humano e o mundo natural (SASS, 2008, p. 43).

Por sua vez, na constituição da Idade Média a natureza passou a ser compreendida como uma criação divina, sendo o universo regido por forças de causas e efeitos sob a égide da Divina Providência; compreendia o homem como um ser superior, por ser filho de Deus, criado à sua imagem e à sua semelhança. Diante desse pensar, inicia-se o afastamento do homem em relação à natureza em um ambiente marcado pelo teocentrismo (GOMES, 2013, p. 31-33). Isto posto, a noção de um universo orgânico, vivo e espiritual foi substituída pelo paradigma cartesiano mecanicista e pela noção de mundo como uma máquina, e a máquina do mundo tornou-se a metáfora dominante da era moderna (CAPRA, 1996, p. 34).

A mudança subsequente ocorre na superação do teocentrismo na Idade Moderna, quando o homem passa a ser considerado a base do universo e a natureza a ser compreendida como um objeto de exploração para mais desenvolvimento (GOMES, 2013, p. 32-36). Além disso, no final do século 18, o movimento romântico na arte, na literatura e na filosofia opõe-se fortemente ao paradigma cartesiano mecanicista, que retorna com força na segunda metade do século 20 (CAPRA, 1996), evidenciando a Idade Contemporânea. Desde a concepção da globalização da natureza, Porto-Gonçalves (2015, p. 23) sugere quatro etapas:

1) O Colonialismo e a Implantação da Moderno-Colonialidade (do século 15-16 a século 17... até hoje);

2) O Capitalismo Fossilista e o Imperialismo (do século 18 ao início do século $20 \ldots$ até hoje);

3) O Capitalismo de Estado Fossilista Fordista (de 1930 aos anos de 1960-1970... até hoje);

4) A Globalização Neoliberal ou Período Técnico-científico-informacional (dos anos 1960 até hoje).

É nessa ambiência que os marcos do entendimento humano sobre a natureza estiveram acompanhados por correntes do pensamento ambiental, ou seja, a doutrina ética ambiental. Essas correntes distinguem-se em antropocentrismo, biocentrismo e ecocentrismo.

\footnotetext{
Há de compreender-se os conceitos de meio ambiente e de natureza para concebê-los no âmbito do Direito. Meio ambiente é o conjunto de fatores externos (materiais, orgânicos, históricos, culturais ou ideológicos) exercendo uma forte influência nos indivíduos). Em outras palavras, constitui o universo característico de cada espécie, tal como o percebe em seu meio vital e graças ao qual pode agir eficazmente (JAPIASSÚ; MARCONDES, 2008, p. 183). Natureza é o mundo físico, como conjunto dos reinos mineral, vegetal e animal, considerado como um todo submetido a leis, as "leis naturais" (em oposição às leis morais e às leis políticas) (JAPIASSÚ; MARCONDES, 2008, p. 198). Assim sendo, o meio ambiente é um espaço de interação dos seres vivos submetidos a fatores antrópicos, e a natureza o ambiente em suas condições naturais, sem intervenção antrópica. Enquanto o direito ambiental tem como objetivo proteger os danos ao meio ambiente, um bem jurídico, os direitos da natureza protegem a natureza tendo em conta sua condição de sujeito de direito.
} 
O Antropocentrismo é a concepção genérica que entende o homem como centro do universo, sua referência máxima e absoluta de valores; assim, os demais seres e forças gravitam ao redor de um eixo central, que é o homem (MILARÉ, 2014, p. 106). Nessa concepção, o homem assume a postura de superioridade absoluta perante os outros seres, e, por conseguinte, atribui-se a ele uma posição de prevalência sobre a natureza. ${ }^{2}$

Essa corrente, significantemente presente na Idade Média, ganha solidez no Período Moderno diante da racionalidade científica ${ }^{3}$, que compreende o homem como um ser vivo superior às demais formas de vida, e a natureza um instrumento de dominação para um desenvolvimento sem limites. Aqui, vale a pena assinalar o início da globalização da dominação da natureza que consolida a hegemonia europeia no mundo, a preço de escravidão e genocídio dos povos indígenas, com a consequente desorganização das sociedades originárias e a exploração de seus recursos naturais (PORTO-GONÇALVES, 2015, p. 24-25).

Contrário ao antropocentrismo, o biocentrismo não estipula valor instrumental aos seres vivos e reconhece a existência de deveres dos seres humanos perante as diferentes formas de vida. Assim, a vida é considerada o centro de todo o valor. Sob essa perspectiva, a vida do ser humano não serve como justificativa para ignorar ou desrespeitar a vida de outros seres vivos (ALMEIDA, 2005, p. 97), tendo em conta que o homem é tão somente um elemento que integra um ecossistema. Esse entendimento, no entanto, por estar restrito à proteção de apenas uma parte da biosfera (os seres vivos), não chegou a lançar raízes profundas, diferente do que ocorreu com o ecocentrismo (MILARÉ, 2014, p. 108).

O ecocentrismo significa redimensionar o lugar do humano nas relações com os demais seres vivos, e estendendo-se a outros elementos que integram a natureza, como as rochas, o solo, a água e seus processos biológicos. Assim, esse paradigma passa a entender o planeta como uma totalidade constituída de partes que se relacionam entre si, uma célula viva que requer ações de preservação e conservação. Esse padrão, que muda (ou deveria mudar) a visão mecanicista para a holística e ecológica, passa a ver o mundo como uma rede, a qual exige um pensamento sistêmico da ciência moderna (CAPRA; MATTEI, 2018).

Nessa breve passagem pelo pensamento da humanidade sobre a natureza, que defronta-se não somente com a sua dominação da natureza, mas também com a dominação de homens sobre homens, de homens sobre mulheres, de algumas culturas sobre outras, uma coisa é certa: além da necessária complexidade científica dos campos do saber para compreender a natureza, a sua proteção passa pelo direito em suas expressões materiais e processuais conforme o paradigma ambiental.

\section{DIREITOS DA NATUREZA: A NATUREZA COMO SUJEITO DO/NO DIREITO}

A corrente de pensamento que compreende os direitos da natureza e a natureza como um sujeito de direitos é a ecocêntrica. Essa corrente, conforme o entendimento de Garzón (2017, p. 15), influenciou, entre outros instrumentos normativos, a Carta da Natureza das Nações Unidas de 1982, que compreende a espécie humana como parte da natureza e que a vida necessita de funcionamento ininterrupto dos sistemas naturais, além de advertir que toda a forma de vida é única e deve ser respeitada, independentemente de sua serventia ao ser humano. Para dar cabo à execução desse pensamento, notadamente afeito à superação do antropocentrismo, entende-se que os direitos da natureza e a natureza como sujeito de direito precisam ser reconhecidos, o que encerra o alargamento dos sujeitos caracterizados como de direitos e deveres, até então representados por seres humanos e entidades públicas ou privadas.

\footnotetext{
2 Ainda quanto à perspectiva de entendimento sobre o antropocentrismo, Leite (2015, p. 384-391) apresenta três modelos axiológicos, quais sejam: o antropocentrismo clássico, o antropocentrismo alargado e o não antropocentrismo. 0 antropocentrismo clássico tem como principal característica a ruptura entre o homem e a natureza, sendo o homem considerado o senhor do universo e, por conseguinte, proprietário da natureza. $\mathrm{O}$ antropocentrismo alargado é uma nova perspectiva ética do homem e da natureza que busca a superação da limitação antropocêntrica, admitindo a proteção da natureza por seu valor intrínseco, almejando a interação entre esses universos distintos e abandonando as ideias, apregoadas no antropocentrismo clássico, de separação, domínio e submissão. O não antropocentrismo refere-se às correntes que criticam a doutrina antropocêntrica, tais como o biocentrismo e o ecocentrismo.

3 Segundo Sass (2008, p. 49), foi a racionalidade científica que buscou desvendar, por intermédio da ciência, os enigmas associados com o mundo ao seu redor, e que permitiu transformar a natureza em objeto de observação e de análise, a ser fragmentado e apropriado. Capra (1996, p. 34) sustenta que foram as descobertas em física, astronomia e matemática, conhecidas como Revolução Científica, associadas aos nomes de Copérnico, Galileu, Descartes, Bacon e Newton, que promoveram esta mudança.
} 


\section{Debate}

Oliveira (2017, p. 129) assegura que a expressão "direitos da natureza" não é criação peruana ou boliviana. A expressão, rights of nature aparece bem antes; é o título de um famoso livro, escrito por Roderick Nash, professor da Universidade da Califórnia, Santa Bárbara, publicado nos Estados Unidos em 1989: Rights of nature: a history of Environmental Ethics.

São direitos que exigem do ser humano um comportamento vinculado à ética da vida, à ética ecológica e à responsabilidade e solidariedade ambiental num espaço de pensar sistêmico. Reclamam o que Capra e Mattei (2018, p. 211) propõem: que as instituições jurídicas gerem incentivos para o comportamento ecologicamente sustentável das pessoas. Os commons ${ }^{4}$ podem ser uma instituição desse tipo. Significam direitos que rompem com a estrutura clássica da Teoria do Direito, sobretudo no campo dos sujeitos, dos bens, da propriedade e da responsabilidade.

Enfim, "são uma categoria de igual valor normativo que a dos direitos humanos. Isto é, os direitos da natureza têm um mesmo valor global que todos os direitos do homem" (PASTOR, 2019, p. 148 - tradução nossa), e, assim sendo, deve-se entender direitos relacionados. Nessa perspectiva, também exigem conciliação com o Direito Ambiental, aquele que vai tutelar o meio ambiente para o cumprimento dos direitos da natureza.

Nessa direção, os direitos humanos individuais e coletivos devem estar em harmonia com os direitos de outras comunidades naturais da Terra; os ecossistemas têm direito a existir e seguir seus próprios processos vitais; a diversidade da vida expressada na Natureza é um valor em si mesmo; e os ecossistemas têm valores próprios que são independentes da utilidade humana (ACOSTA, 2019, p. 166 - tradução nossa).

Foi na América Latina que algumas constituições, como a do Equador e da Bolívia, ultrapassaram o entendimento jurídico clássico da natureza como bem jurídico. Desde outro continente, somam-se a Nova Zelândia e a Austrália em seus sistemas de comon law.

A Constituição do Equador, no ano de 2008, reconheceu expressamente os direitos da natureza em sua Constituição, bem como identificou a natureza como um sujeito de direito ${ }^{5}$. A referida Lei considera direitos da natureza: i) el derecho a su existencia y tener defensores (Art. 71); ii) el derecho a la restauración sin ignorar el derecho de las comunidades a una reparación total (Art. 72); iii) el derecho a la precaución y a aplicar restricciones (Art. 73); iv) el derecho a no ser comercializado; $y$ v) permitir actividades humanas y comunitarias dentro del alcance de sumak kawsay (Art. 74) (ECUADOR, 2008).

Por sua vez, a Constituição Boliviana de 2009, ainda que não tenha afirmado expressamente os direitos da natureza, estabelece suas normas em estreito vínculo com a Madre Tierra, a Pachamama, ${ }^{6}$ em direção ao buen vivir. Por conseguinte, motiva a aprovação da Lei 071 de 2010 (BOLÍVIA, 2010), que reconhece os direitos da Madre Tierra, impõe obrigações e deveres ao Estado plurinacional e à sociedade para garantir o respeito desses direitos e reconhece seu caráter jurídico. ${ }^{7}$ A mencionada Lei limita o exercício dos direitos individuais em relação aos coletivos e determina que qualquer conflito entre direitos deve resolver-se de maneira que não afete a funcionalidade dos sistemas de vida. Igualmente, vale mencionar que, na Colômbia, a Corte Suprema, em 2018, confirmou a Amazônia colombiana como entidade sujeito de direitos em questões relativas às mudanças climáticas (COLÔMBIA, 2018).

\footnotetext{
Sem pretender esgotar o tema, que pode ser estudado no livro dos referidos autores (página 211 em diante), não há nenhuma definição jurídica reconhecida, mas os estudiosos do direito concordam, em grande parte, que os commons não são nem privados nem públicos.

La naturaleza será sujeto de aquellos derechos que le reconozca la Constitución (art. 10) (ECUADOR, 2008).

6 O Preâmbulo assinala: [...] Nuestra amazonia, nuestro chaco, nuestro altiplano y nuestros llanos y valles se cubrieron de verdores y flores. Poblamos esta sagrada Madre Tierra con rostros diferentes, y comprendimos desde entonces la pluralidad vigente de todas las cosas y nuestra diversidad como seres y culturas. [...] Cumpliendo el mandato de nuestros pueblos, con la fortaleza de nuestra Pachamama y gracias a Dios, refundamos Bolivia [...]. Ademais, o artigo 255, II vincula os tratados internacionales à "Armonía con la naturaleza, defensa de la biodiversidad, y prohibición de formas de apropiación privada para el uso y explotación exclusiva de plantas, animales, microorganismos y cualquier materia viva" (BOLÍVIA, 2009).

Artículo 5. (CARÁCTER JURÍDICO DE LA MADRE TIERRA). Para efectos de la protección y tutela de sus derechos, la Madre Tierra adopta el carácter de sujeto colectivo de interés público. La Madre Tierra y todos sus componentes incluyendo las comunidades humanas son titulares de todos los derechos inherentes reconocidos en esta Ley. La aplicación de los derechos de la Madre Tierra tomará en cuenta las especificidades y particularidades de sus diversos componentes. Los derechos establecidos en la presente Ley, no limitan la existencia de otros derechos de la Madre Tierra (BOLÍVIA, 2010).
} 
Na Nova Zelândia, a sessão 11 do Te Urewera Act, de 2014, reconhece que a Urewuera, uma região montanhosa do país, possui todos os direitos, poderes, deveres e responsabilidades de uma pessoa jurídica, os quais serão exercidos e executados pelo Conselho Te Urewera (NOVA ZELÂNDIA, [2014]). Nessa linha, em 2017, após 140 anos de negociações, o rio Whanganui (também chamado Te Awa Tupua), considerado sagrado para os povos indígenas Maori, foi reconhecido como entidade viva a ser protegida, de modo a garantir a continuidade da sua existência. Ainda, ao rio foi conferida identidade jurídica, sendo também considerado detentor de direitos, deveres e responsabilidades como qualquer outra pessoa jurídica (SANTOS, 2019, p. 55). O Te Awa Tupua Act (Whanganui River Claims Settlement) 2017, em sua sessão 14, reconhece a personalidade jurídica do rio e seus direitos e deveres (NOVA ZELÂNDIA, [2017]). Na Austrália, este reconhecimento ficou por conta do Yarra River Protection Act 2017.

Isso posto, os direitos da natureza atravessam o paradigma de proteção ambiental para a manutenção da vida humana e viabilizam mais uma dimensão para a reivindicação e efetivação da necessária conservação da natureza. O homem passa a ser compreendido como um integrante da natureza e o "mundo como um todo integrado, e não como uma coleção de partes dissociadas" (CAPRA, 1996, p. 25). Os mencionados países apresentados prosperam o paradigma da ética ambiental ecocêntrica, que pressupõe a ética da vida, a responsabilidade e a solidariedade ambiental, a justiça socioambiental e a descolonização e decolonialidade da natureza.

Como dito, em que pese o Brasil não reconhecer a natureza como um sujeito de direitos, o Poder Judiciário vem sendo provocado para se manifestar, especialmente em licenciamentos e conflitos ambientais territoriais.

Segundo Ferreira (2013, p. 417), a primeira vez que os direitos da natureza foram suscitados ao Judiciário brasileiro foi na Ação Civil Pública interposta pelo Ministério Público do Pará, no dia 17 de agosto de 2011 (BRASIL, 2011).

Nessa ação, o Ministério Público Federal, como forma de fundamentar o pedido de suspensão das obras, sustentou que "a humanidade caminha para o reconhecimento da natureza como um sujeito de direitos" (BRASIL, 2011, p. 25), argumento que objetivava impedir a construção do aproveitamento hidrelétrico Belo Monte pela concessionária Norte Energia S.A., pois atingiria a Volta Grande do Xingu. Na sentença proferida em 8 de julho de 2014 (BRASIL, 2014), o magistrado alegou que "o argumento de ser a Volta do Xingu sujeito de direitos não pode ser acatado como fundamento para a acolhida do pedido formulado". Além disso, por compreender que as ilegalidades não ficaram evidenciadas, julgou improcedente os pedidos da inicial.

Posteriormente, em 7 de novembro de 2017, a Bacia Hidrográfica do Rio Doce solicita ao Judiciário o seu reconhecimento como sujeito de direitos (BRASIL, 2017), sendo representado pela Associação Pachamama. ${ }^{8}$ Na petição, como recurso natural, a Bacia demonstra sua essencialidade a 3,5 milhões de pessoas, aos processos ecológicos, à biodiversidade e aos povos que vivem na sua margem. Fundamentou-se na Convenção 169 da OIT (artigo 13), que obriga o Estado a respeitar a importância espiritual que a terra tem para os povos indígenas e tribais. Ademais, respaldou seu pedido na Constituição Federal, alegando que o Estado brasileiro deve proteger a vida, os modos ancestrais de criar, fazer e viver, os espaços de manifestações culturais ancestrais, os processos ecológicos essenciais, a biodiversidade e os recursos ambientais necessários à reprodução física e cultural dos povos ancestrais, segundo os seus usos, costumes e tradições. Ainda, demonstrou os prejuízos que a empresa Samarco Mineração S.A. provocou à Bacia, em razão do rompimento de sua barragem de rejeitos.

\footnotetext{
8 A Associação Pachamama é uma organização que semeia e desperta consciências das maravilhas da Madre Tierra, baseadas pelos princípios do Bem Viver. Trabalham para uma interligação humana, ligada aos pilares da vida, seja ela ecológica, social ou humana. Está sediada na cidade de Pelotas/RS. Disponível em: https://www.ongpachamama.org/quem-somos. Acesso em: 13 ago. 2019.
} 
Quanto aos pedidos, a Bacia Hidrográfica do Rio Doce solicitou o reconhecimento e a procedência da ação; liminarmente requereu o seu reconhecimento como sujeito de direitos e o reconhecimento da ampla legitimidade de pessoas defenderem o seu direito à existência; ${ }^{9}$ e a condenação da União e do Estado de Minas Gerais ao cumprimento de diretrizes do Plano Nacional de Adaptação à Mudança do Clima. Na sentença, a magistrada alegou ausência de pressuposto processual de existência:

2.11. A legislação vem evoluindo e é perceptível a mudança de uma visão puramente antropocêntrica para um pensamento concebido no princípio de que há uma importante e estrita relação entre o homem e o universo, donde se percebe o homem como um ser que do universo faz parte e com ele interage.

2.12. Mas ainda assim, o nosso ordenamento jurídico não conferiu aos demais seres vivos, como animais, florestas, mares e rios os atributos da personalidade [...];

2.16. Entretanto, para ser parte (personalidade judiciária ou personalidade jurídica), necessária a capacidade do sujeito de gozo e exercício de direitos e obrigações, o que não se verificou in casu [...];

2.19. Trata-se de um pressuposto processual de existência da ação [...];

2.220 ordenamento jurídico pátrio não conferiu aos animais, florestas, plantas, rios e mares os atributos da personalidade, por conseguinte, a Bacia Hidrográfica do Rio Doce não possui personalidade jurídica ou personalidade judiciária que lhe permita requerer a tutela jurídica [...];

2.28. Talvez ninguém ame mais um rio que esta juíza.

2.29. Mas ao menos juridicamente, o rio não pode postular perante o juízo os seus direitos. Este nobre encargo, conforme anteriormente salientado, restou constitucionalmente determinado aos legitimados à defesa do meio ambiente e dos interesses difusos e coletivos, entre eles, as associações [...];

2.31. Com estas considerações, verifico ausência de pressuposto processual de existência, uma vez que o ordenamento jurídico não confere à requerente "Bacia Hidrográfica do Rio Doce" personalidade jurídica [...];

3.1. Por tais razões, indefiro a petição inicial e julgo extinto o processo, sem resolução de mérito, nos termos do art. 485, I e IV, do CPC (BRASIL, 2018).

Como observa-se, as decisões não reconhecem a natureza como sujeito de direitos e seguem compreendendo a personalidade, atributo de um sujeito de direitos (pessoas físicas e jurídicas), em conformidade com o direito nacional. Nessa conjuntura, observa-se que as decisões apresentadas às Ações Civis Públicas propostas por elementos da natureza deixam de cumprir com a justiça socioambiental. Ademais, desde as referidas proposituras de ações, as respostas jurisdicionais não resolveram o problema do dano e, por consequência, a não efetivação dos direitos da natureza e da justiça socioambiental.

Diante de tal insucesso, há de mencionar-se alguns progressos, ainda que apenas relacionados aos animais não humanos: i) a aprovação pelo Senado brasileiro, em agosto de 2018, do Projeto de Lei que cria o regime especial para os animais. Segundo o artigo terceiro, os animais não humanos possuem natureza jurídica sui generis e são sujeitos de direitos despersonificados, dos quais devem gozar e obter tutela jurisdicional em caso de violação, vedado o seu tratamento como coisa (BRASIL, 2018) e; ii) o reconhecimento pelo STF (REsp 1.797.175/ SP) da dimensão ecológica da dignidade da pessoa humana e da vida em geral e a titularidade de direitos e de dignidade aos animais não humanos e, por conseguinte, seu status jurídico de sujeito de direitos (BRASIL, 2019).

Por fim, sustenta-se que o reconhecimento dos direitos da natureza e da natureza como um sujeito de direitos, pode ser um potencial promotor na ampliação do acesso à justiça ao Poder Judiciário para o cumprimento dos direitos da natureza e da justiça socioambiental. A seguir, examina-se esta questão.

\section{CONSIDERAÇÕES SOBRE O ALARGAMENTO DO ROL DOS SUJEITOS DE DIREITO PARA O ACESSO À JUSTIÇA E À JUSTIÇA SOCIOAMBIENTAL}

Mauro Cappelletti e Bryant Garth $(1988$, p. 8) admitem que "a expressão 'acesso à justiça' é reconhecidamente de difícil definição", mas determinam que sua finalidade seja a reivindicação dos direitos pelas pessoas e a resolução dos litígios pelo Estado. O problema, entretanto, translada-se aos direitos difusos. Sobre

\footnotetext{
A alegação está amparada no direito comparado, pois a corte constitucional da Colômbia (de forma similar à Nova Zelândia) reconheceu o Rio Atrio como um sujeito de direito biocultural. Do mesmo modo, nos acordos internacionais que a Colômbia aderiu, pois são os mesmos de que o Brasil faz parte. Por mais, a Colômbia determinou a proteção do Rio a uma "comissão de guardiães", o que justifica o pedido da ampla legitimidade de pessoas para defender o Rio Doce.
} 
isto vale lembrar que, há 25 anos, mais de 30.000 habitantes da Amazônia equatoriana mantêm uma batalha jurídica contra a Chevron em um contexto de obstáculos ao acesso à justiça sem precedentes, e de processos entrelaçados em alta complexidade (GUAMÁN; APARÍCIO, 2019, p. 250).

Durante os séculos 18 e 19, nos estados liberais burgueses, as soluções de litígios refletiam uma filosofia individualista dos direitos, pois o acesso à proteção judicial estava restrito ao direito formal do indivíduo em propor e contestar uma ação. Ao Estado cabia um papel passivo, apenas manifestando-se quando provocado. Também, a justiça somente poderia ser obtida por aqueles com capacidade de enfrentar seus custos, estando adstrita ao procedimento estabelecido em lei, não havendo preocupação com as problemáticas enfrentadas pela maioria da população, as quais eram incapazes de suportar os gastos processuais para terem seus conflitos solucionados pelo Estado (CAPPELLETTI; GARTH, 1988, p. 9-10).

$\mathrm{Na}$ medida em que as sociedades liberais cresceram em tamanho, também cresceram em complexidade. As ações, que antes retratavam a filosofia individualista, passam a assumir um caráter coletivo, o que influenciou certa transformação no direito e a consequente positivação dessas mudanças nos ordenamentos jurídicos, efetuando-se o reconhecimento dos direitos e deveres sociais dos governos, das comunidades, das associações e dos indivíduos. Diante dessas transformações, as constituições modernas inseriram em seus textos os direitos ao trabalho, à saúde, à segurança material e à educação, o que refletiu na necessidade de atuação positiva por parte do Estado para assegurar o gozo desses direitos (CAPPELLETTI; GARTH, 1988, p. 10-11).

O surgimento de novos direitos exigiu um outro comportamento do Estado. Ou seja, a partir do momento em que o Estado reconhece novos direitos, passa a ter por missão assegurá-los e o Poder Judiciário efetivá-los quando acionado. Nesse sentido, Boaventura de Sousa Santos $(2014$, p. 4) entende que "por reunir as tensões e disjunções do conflito entre justiça procedimental e justiça material, o acesso à justiça é uma janela analítica privilegiada para se discutir a reinvenção das bases teóricas, práticas e políticas de um pensar radical do direito".

A mudança não ocorre somente sob a perspectiva de atuação do Estado em assegurar direitos, mas, também, no que se refere ao conceito de acesso à justiça, pois passa a ser compreendido como o modo pelo qual os direitos tornam-se efetivos quando descumpridos. Diante disso, o acesso à justiça afasta-se da compreensão de um direito privatístico e avança para o coletivista, à medida que é reconhecido como um direito social, e caracterizado como o ponto central de uma nova teoria do processo judicial (SANTOS, 2014).

Nessa linha, Cappelletti e Garth (1988, p. 13) expõem que “o 'acesso' não é apenas um direito fundamental, crescentemente reconhecido; ele é, também, necessariamente, o ponto central da moderna processualística. Seu estudo pressupõe um alargamento e aprofundamento dos objetivos e métodos da moderna ciência jurídica".

No Brasil, em meio à redemocratização do país, observou-se uma nova tendência de instrumentalizar o direito processual. De acordo com Dierle Nunes (2012, p. 141), esse movimento foi influenciado por Mauro Cappelletti e trouxe, para o ordenamento jurídico brasileiro, a aprovação da Lei de Ação Civil Pública (Lei 7.347/85) e outras reformas processuais.

Apesar disto, as reformas processuais ocorridas nas últimas décadas do século 20 , demasiadamente comprometidas com o eficientismo neoliberal, tal qual a lógica de mercado, primaram pela celeridade dos procedimentos em detrimento da efetividade. Nesse contexto, questões processuais voltadas para a proteção dos difusos e coletivos, nos quais se incluem o meio ambiente, não obtiveram a devida atenção, razão pela qual algumas amarras da ciência processual de cunho individualista, próprias dos séculos passados, ainda estão presentes no ordenamento jurídico.

A busca de efetividade dos direitos da natureza também passa pelo "direito à remoção de todos os obstáculos que se anteponham ao acesso efetivo à justiça com tais características" (WATANABE, 2019, p. 10). 0 acesso à justiça adequado pode pressupor efetivos os direitos da natureza e, em consequência, possibilitar a justiça socioambiental, "entendida como a expressão da desigualdade social na apropriação do ambiente e de seus recursos" (RIBEIRO, 2017). Desde outra perspectiva, um conceito político que compreende os recursos naturais como bens coletivos, cujos modos de apropriação e gestão devem ser objeto de debate público e controle social, reafirma os direitos das populações do campo e da cidade a uma proteção equânime contra a discriminação socioterritorial e a desigualdade ambiental (MALERBA, 2010, p. 17). 
Afinal, o Sistema de Justiça não pode, em sua prestação jurisdicional, prestar a "justiça social sem ter em conta a justiça ambiental ou ecológica e ambas devem ser compreendidas em sua inter-relação com a justiça cultural, que implica o reconhecimento de igualdade política dos povos e culturas" (GUAMÁN; APARÍCIO, 2019, p. 235, tradução nossa).

Sustenta-se que o acesso à justiça promove a justiça socioambiental, posto que, ao providenciar a defesa do meio ambiente e reprimir ou reparar danos, ampara a efetivação dos direitos da natureza. Estes direitos conseguem investir contra as desigualdades ambiental e social na medida em que podem impor que as atividades humanas estejam em acordo com a capacidade de regeneração dos recursos naturais e com a distribuição justa e equitativa destes recursos.

Cotejando essas vertentes propositivas, é possível afirmar que o acesso à justiça necessita da superação de alguns obstáculos de natureza processual. Daí que se propõe, a partir da análise das ondas renovatórias de Mauro Cappelletti, soluções possíveis na eliminação destes obstáculos para garantir a defesa dos direitos da natureza em juízo e promover a justiça socioambiental.

\subsection{As Ondas Renovatórias para o Acesso à Justiça}

Para compreender as dificuldades enfrentadas na efetivação do acesso à justiça, Cappelletti e Garth (1988) realizaram um estudo comparado, intitulado Projeto Florença, o qual identificou soluções práticas que alguns países adotaram para melhor enfrentar o acesso à justiça. Nesse estudo, identificam três obstáculos principais: as custas judiciais, a possibilidade das partes e os interesses difusos, e apresentam movimentos de reformas processuais chamados de ondas renovatórias, para, então, superar os obstáculos ao acesso à justiça.

Diante desses aspectos, o estudo observou a adoção de medidas resolutivas em períodos similares por países diversos, o que foi denominado pelos autores de ondas renovatórias. A primeira solução observada para o problema da inefetividade do acesso à justiça, a primeira onda, foi a introdução da assistência judiciária; a segunda destacou a representação jurídica em interesses difusos; e a terceira propôs as advocacias judicial e extrajudicial para processar e prevenir disputas nas sociedades modernas.

Neste trabalho interessa-nos analisar a segunda onda, que investiu nos direitos difusos e coletivos e deu espaço para a coletividade da tutela em resistência ao processo privatístico. No estado brasileiro, o direito difuso $^{10}$ a um meio ambiente equilibrado introduziu a segunda onda no seu ordenamento jurídico por meio da Ação Civil Pública, da Ação popular e do Mandado de Segurança Coletivo.

A segunda e terceira ondas propõem a necessária adaptação do processo civil aos tipos de litígios (CAPPELLETTI; GARTH, 1988, p. 71), e no Brasil observa-se esta adequação nas Leis da Ação Civil Pública, da Ação popular e no Mandado de Segurança Coletivo, que permitem a ação coletiva, e no Termo de Ajustamento de Conduta (TAC), previsto na Lei de Ação Civil Pública, que possibilita a composição extrajudicial do conflito.

Não obstante, os três instrumentos processuais originados da segunda onda têm limitações; uma delas é a legitimidade de ação, para o que se propõe um alargamento do rol de sujeitos aptos a ingressar com uma ação coletiva de repressão ou recuperação de atos lesivos ao meio ambiente e aos direitos da natureza.

\subsection{Os Sujeitos de Direito no Ordenamento Jurídico Brasileiro}

Em matéria de proteção ambiental, sem dúvida a restrição da legitimidade de agir com essa finalidade constitui, ainda, no âmbito do acesso à justiça, o maior entrave.

Estabelece o ordenamento jurídico brasileiro, em seu Código Civil, artigo 1ํ, que "toda pessoa é capaz de direitos e deveres na ordem civil" (BRASIL, 2002).

A partir da inteligência do referido artigo, verifica-se que o ordenamento pátrio entende que toda pessoa, excetuadas as definidas como incapazes, é sujeito de direitos e de obrigações, estabelecendo intrínseca relação entre sujeito, direito e obrigação. $O$ atributo pessoa, no entanto, não se restringe apenas aos humanos, pois nosso ordenamento confere o título de pessoa tanto para as naturais quanto para as jurídicas, o que

\footnotetext{
10 Segundo Roberto Barroso (2019, p. 499), os direitos difusos caracterizam-se por pertencerem a uma série indeterminada de sujeitos e pela indivisibilidade do seu objeto, e a satisfação implica a satisfação de todos, à medida que a lesão de um só constitui lesão da coletividade.
} 
evidencia que o quesito humanidade não é o cerne para o reconhecimento de um sujeito de direitos. No ordenamento jurídico nacional, apenas estas pessoas, a natural e a jurídica, usufruem de personalidade jurídica, atributo que as reconhece como um sujeito de direito apto para alcançar a justiça.

Assim sendo, o quesito necessário para o reconhecimento de um sujeito, que encontra relação com direitos e obrigações, é a personalidade. Nesse sentido, Clóvis Beviláqua $(1999$, p. 80) estabelece que pessoa é o ser a quem se outorgam direitos e obrigações; já a personalidade corresponde à aptidão, reconhecida pelo ordenamento jurídico a alguém para exercer direitos e contrair obrigações. Ou seja, para ser categorizado como pessoa e ter personalidade jurídica, é necessário, previamente, o seu reconhecimento pelo ordenamento jurídico.

Como estudou-se, a natureza carece de reconhecimento como sujeito de direito no ordenamento jurídico brasileiro, posto que nenhuma fonte de direito lhe admite personalidade jurídica. Logo, para acessar a justiça na repressão ou reparação de danos ambientais, a natureza necessita ser representada pelos legitimados a propor ação conforme um dos instrumentos de demanda coletiva.

\subsection{Ação Civil Pública e Necessárias Reformas}

O instrumento mais utilizado em matéria ambiental é a Ação Civil Pública, a qual daremos especial atenção. A Ação Civil Pública, que constitui um "marco inicial da defesa dos direitos supra-individuais no direito brasileiro" (FERRARESI, 2009, p. 199), é um procedimento coletivo regulado pela Lei 7.347 (BRASIL, 1985) para a tutela processual de direitos difusos e coletivos, entre outros, o meio ambiente.

Essa Lei estabelece um rol taxativo de legitimados para a propositura da ação, quais sejam: o Ministério Público, a Defensoria Pública, a União, os Estados, o Distrito Federal, os Municípios, as autarquias, as empresas públicas, as fundações, as sociedades de economia mista e as associações (as constituídas há pelo menos um ano e que, dentro de suas finalidades institucionais, esteja incluída a proteção que irá pleitear).

É um instrumento capaz de gerar responsabilidade por danos morais e patrimoniais, rompendo "mais formalmente com a tradição individualista que informa o sistema processual civil brasileiro" (ANTUNES, 2019, p. 329). Apesar disso, limita o acesso à justiça em dois aspectos essenciais, isto é, ao apresentar um rol taxativo de legitimados e ao determinar que as associações tenham expressa finalidade de proteção ambiental para a proposição de Ação Civil Pública, sob pena de, quando não observados esses requisitos, ocasionar o não conhecimento da ação. Não trataremos desta segunda limitação.

Assim, esse instrumento processual admite pessoas jurídicas públicas ou privadas para figurarem no polo ativo das demandas judiciais, adotando o modelo misto. Não obstante, afasta a legitimidade das pessoas físicas no ajuizamento de ações coletivas, mesmo que essas detenham a titularidade do direito difuso levado ao apreço do Judiciário.

Outra questão complexa presente na referida Lei é o instituto da representação adequada, que, no Brasil é presumida na figura dos legitimados ativos, a critério do legislador e sem o consentimento dos cidadãos que são substituídos processualmente. Nesse sentido, Santos (2016, p. 197) entende que "um dos maiores entraves à incorporação do procedimento coletivo diz respeito à representatividade das coletividades".

Santos (2016, p. 208) explica que a representatividade adequada não é imanente da legitimidade ativa conferida pelo rol legal, assim como não está o juízo adstrito à confirmação da legitimidade ativa do demandante, mas, sim, resulta de uma análise acerca da fidelidade do legitimado para com a causa coletiva, ou seja, o legitimado deve ser intimado para demonstrar sua condição de representante adequado e, caso suas justificativas não sejam acolhidas, deve-se preservar o processo já ajuizado com a substituição do mesmo, sob pena de extinção da causa sem análise de mérito por falta de interesse de agir.

Convém deixar claro que não existem critérios legais para a análise da representatividade adequada no Brasil, o que reforça a necessidade de um alargamento de legitimados para exercer o direito de acesso à justiça, especialmente em causas que tratem de prevenção ou reparação de danos ao meio ambiente em benefício dos direitos da natureza. A complexidade da natureza, uma totalidade integrada, exige um autor da ação experiente na particularidade. 


\section{Direito目

Em síntese, a natureza, teia interconexa de relações entre sistemas vivos - organismos, partes de organismos ou comunidade de organismos (CAPRA, 1996) - reclama cuidado, responsabilidade e solidariedade ao ser manejada. Esses valores, em consequência, reivindicam conhecimento especializado do legitimado ativo em uma Ação Civil Pública ambiental, que deve bem representar a coletividade. Aliás, tais valores, num mundo em rede, merecem um ordenamento ecojurídico baseado no reconhecimento de que a sobrevivência humana neste planeta não está assegurada, tendo em vista a destruição da vida e o domínio da natureza que tanto caracterizam a atual tendência desenvolvimentista (CAPRA, MATTEI, 2018, p. 43).

O processo coletivo requer um olhar que ultrapassa a tradição privatística do direito processual, notadamente quando está em questão um interesse de caráter difuso que assegura diversos direitos constitucionais, e um objeto que tem vida e é digno de direitos: a natureza. É sob essa perspectiva, e tendo em conta que a condição de ser humano não pode ser o núcleo do reconhecimento de um titular de direitos e deveres, que se propõe um alargamento dos legitimados em Ação Civil Pública que leve em consideração a natureza como um sujeito de direitos, tal como os países supraestudados.

Claro está que uma árvore, um rio, um conjunto de montanhas, por exemplo, não podem cogitar um pedido diante o Poder Judiciário e, assim, efetivar o acesso à justiça; a natureza dependerá de legitimados processuais qualificados para agir em seu nome, seja para reprimir ou recuperar um dano ambiental, seja para preveni-lo. Resulta que este pedido precisará estar acompanhado de defensores, tal é o Conselho de Pesca e Caça na Nova Zelândia e a Defensoria da Madre Tierra na Bolívia, e que poderia avançar para as organizações não governamentais, comunidades tradicionais investidas na condição de associação e movimentos sociais. Dessa maneira, as necessárias reformas processuais em Ação Civil Pública são alcançadas, quais sejam, o reconhecimento da natureza como um sujeito de direito e a representatividade adequada.

Essa reflexão vai, inclusive, ao encontro de uma nova proposta de acesso à justiça que está em andamento, por iniciativa de Bryan Garth. O Global Project Acess to Justice ${ }^{11}$ reúne diversos profissionais em todo o mundo e adianta a perspectiva de novas ondas ou dimensões para garantir a efetivação ampla de direitos. Essa perspectiva inclui, como quinta onda, uma nova dimensão de acesso à justiça voltada para um contemporâneo processo de internacionalização da proteção dos direitos humanos, o que reforça e abre espaço à presente proposta, que eleva a natureza a um patamar de sujeito de direitos e reconhece os seus direitos, os quais devem ter o mesmo valor que os direitos humanos.

Nessa lógica, o arranjo entre direitos humanos, direitos ambientais e direitos da natureza, que refletem o pensamento sistêmico, ecocêntrico, torna-se oportuno para impulsionar uma ecologia do direito e uma adequada justiça socioambiental.

\section{CONCLUSÃO}

Da análise da trajetória do pensamento sobre a natureza depreende-se que sua dominação se inicia na Idade Média, fortemente marcada pelo pensamento antropocêntrico. O Período Moderno segue essa linha e agrega o antropocentrismo alargado e o ecocentrismo, que, apesar de ser um pensamento presente e modelo ideal para a contemporaneidade, não tem o necessário potencial para fixar-se enquanto paradigma global de desenvolvimento. Definitivamente, a crise ambiental não dá sinais de possibilidades de contenção.

As normas processuais de acesso à justiça exigem instrumentos hábeis para adentrar o Sistema de Justiça em questões de prevenção e reparação de dano ambiental, tendo em vista os plausíveis direitos da natureza e a consequente justiça socioambiental. À natureza deve-se um Judiciário de portas abertas em ajuste ao pensamento sistêmico; um Judiciário que abrigue instrumentos e instituições capazes de conduzir o comportamento humano em direção ao ecológica, social e economicamente sustentável, levando em conta a natureza como sujeito de direitos.

Nessas veredas, os direitos da natureza têm especial importância ao serem reconhecidos como titulares de direitos, o que ocorre em alguns países. O Brasil não adota esta postura, apesar dos importantes movimentos neste sentido, destacando-se a recente decisão proferida pelo STF que reconhece a dimensão ecológica da dignidade da pessoa humana e atribui dignidade e direitos a animais não humanos.

Cf. http://globalaccesstojustice.com/?lang=pt-br. Acesso em: 29 maio 2020. 
Atendendo à necessidade do acesso à justiça para prevenir ou recuperar danos ao meio ambiente em cumprimento dos direitos da natureza, sustenta-se que é fundamental a ampliação dos sujeitos a partir do alargamento do rol de legitimados para a proposição de Ação Civil Pública ambiental, principal instrumento processual para a prevenção ou reparação de danos ao meio ambiente. Tem-se que o rol taxativo da Lei que regula esta ação é um limitador de sua propositura e, portanto, um obstáculo de acesso à justiça ainda a ser superado. Sem essa superação, fica difícil garantir uma boa efetividade de proteção ao meio ambiente para os direitos da natureza. Além disso, essa ampliação poderá qualificar o propositor de uma ação no sentido de transcender o obstáculo do instituto da representação adequada.

Assim, em atenção aos direitos da natureza, o Estado brasileiro tem a possibilidade de ascender a uma processualística mais contemporânea. Compreender a natureza como um sujeito de direitos capaz para acessar a justiça é uma qualificada estratégia para promover um acesso à justiça mais amplo e, em consequência, a justiça socioambiental.

\section{REFERÊNCIAS}

ACOSTA, Alberto. Construcción constituyente de los derechos de la Naturaleza. Repasando una historia con mucho futuro. In: ACHURY, Liliana Estupiñana et al. La Naturaleza como sujeto de derechos en el constitucionalismo democrático. Bogotá: Universidad Libre, 2019.

ALMEIDA, António Correia de. Concepções ambientalistas dos professores: suas implicações em educação ambiental. 2005. Tese (Doutorado em Ciências da educação) - Universidade Aberta, Lisboa, 2005. Disponível em: http://hdl.handle. net/10400.2/2484. Acesso em: 1ㅇago. 2019.

ANTUNES, Paulo de Bessa. Direito ambiental. 20. ed. São Paulo: Atlas, 2019.

BARROSO, Luís Roberto Curso de direito constitucional contemporâneo: os conceitos fundamentais e a construção do novo modelo. 8. ed. São Paulo: Saraiva Educação, 2019.

BEVILÁQUA, Clóvis. Teoria Geral do Direito Civil. São Paulo: RED Livros, 1999.

BOLIVIA. Constitución Política del Estado. Ciudad de El Alto de La Paz: Presidencia de la República, 2009. Disponível em: https://www.oas.org/dil/esp/Constitucion_Bolivia.pdf. Acesso em: 17 jun. 2019.

BOLÍVIA. Ley n. 071. Ley de Derechos de la Madre Tierra. Ciudad de El Alto de La Paz: Presidencia de la República, 2010. Disponível em: http://www.planificacion.gob.bo/uploads/marco-legal/Ley\%20N\%C2\%B0\%20071\%20DERECHOS\%20DE\%20LA\%20 MADRE\%20TIERRA.pdf. Acesso em: 24 maio 2019.

BRASIL. Lei 7.347 de 24 de julho de 1985. Ação civil pública (1985). Disciplina a ação civil pública de responsabilidade por danos causados ao meio-ambiente, ao consumidor, a bens e direitos de valor artístico, estético, histórico, turístico e paisagístico (VETADO) e dá outras providências. Brasília, DF, [1985]. Disponível em: http://www.planalto.gov.br/ccivil_03/Leis/L7347orig.htm. Acesso em: 22 dez. 2019.

BRASIL. Lei $n^{\circ} 10.406$ de 10 de janeiro de 2002. Código Civil (2002). Institui o Código Civil Brasília, DF: Presidência da República, [2002]. Disponível em: http://www.planalto.gov.br/ccivil_03/leis/2002//10406.htm. Acesso em: 24 dez. 2019.

BRASIL. Constituição da República Federativa do Brasil de 1988. Brasília, DF: Presidência da República, [2016]. Disponível em: http://www.planalto.gov.br/ccivil_03/Constituicao/Constituiçao.htm. Acesso em: 1o ago. 2019.

BRASIL. Emenda Constitucional no 42, de 19 de dezembro de 2003. Altera o Sistema Tributário Nacional e dá outras providências. Brasília, DF: Mesas da Câmara dos Deputados e do Senado Federal, [2003]. Disponível em: http://www.planalto.gov.br/ ccivil_03/constituicao/Emendas/Emc/emc42.htm. Acesso em: 10 mar. 2020.

BRASIL. Procuradoria da República. Ministério Público Federal. Petição inicial. Processo 28944-98.2011.4.01.3900. Vara Federal da Seção Judiciária do Pará, 17 ago. 2011. Disponível em: http://www.prpa.mpf.gov.br/news/2011/BeloMonte_Remocao.pdf. Acesso em: 26 jul. 2019.

BRASIL. Câmara dos Deputados. Projeto de Lei da Câmara n. 28 de 2018. Acrescenta dispositivo à Lei no 9.605 , de 12 de fevereiro de 1998, para dispor sobre a natureza jurídica dos animais não humanos. Disponível em: https://www25.senado.leg.br/ web/atividade/materias/-/materia/133167. Acesso em: 28 maio 2020.

BRASIL. Superior Tribunal de Justiça. Recurso Especial 1.797.175/SP, 2018/0031230-0 da 2a Turma. 2019. Disponível em: https:// stj.jusbrasil.com.br/jurisprudencia/692205375/recurso-especial-resp-1797175-sp-2018-0031230-0/inteiro-teor-692205385. Acesso em 15 maio 2020.

BRASIL. Seção Judiciária do Estado de Minas Gerais. Petição inicial. Processo 1009247-73.2017.4.01.3800. Vara Federal Cível da Seção Judiciária de Minas Gerais, 5 nov. 2017. 
BRASIL. Seção Judiciária do Estado de Minas Gerais. Sentença. Processo 1009247-73.2017.4.01.3800. Vara Federal Cível da Seção Judiciária de Minas Gerais, 21 set. 2018. Disponível em: https://pje1g.trf1.jus.br/consultapublica/ConsultaPublica/DetaIheProcessoConsultaPublica/listView.seam?ca=984e05c9ec3b3ceda7810b14142ed5c65c0e22752c38b7d6. Acesso em: 19 abr. 2019.

BRASIL. Seção Judiciária do Estado do Pará. Justiça Federal de 1a Instância. Sentença. Processo 28944-98.2011.4.01.3900. Vara Federal da Seção Judiciária do Pará, 8 jul. 2014. Disponível em: https://processual.trf1.jus.br/consultaProcessual/processo. php?proc=289449820114013900\&secao=PA\&nome=NORTE\%20ENERGIA\%20S/A\&mostrarBaixados=S. Acesso em: 26 jul. 2019.

CAPPELLETTI, Mauro; GARTH, Bryant. Acesso à Justiça. Tradução e revisão Ellen Gracie Northfleet. Porto Alegre: Fabris, 1988. CAPRA, Fritjof. A teia da vida. São Paulo: Cultrix, 1996.

CAPRA, Fritjof; MATTEI, Ugo. A revolução ecojurídica: o direito sistêmico em sintonia com a natureza e a comunidade. Tradução Jeferson Luiz Camargo. São Paulo: Editora Cultrix, 2018.

COLÔMBIA. Corte Suprema de Justiça. STC 4360-2018. Radicación n. 11001-22-03-000-2018-00319-01. 10 abr. 2018. Disponível em: http://www.cortesuprema.gov.co/corte/index.php/2018/04/05/corte-suprema-ordena-proteccion-inmediata-de-la-amazonia-colombiana/. Acesso em: 20 maio 2020.

ECUADOR. Constitución de la República del 2008.Assemblea Constituyente. 2008. Disponível em: https://www.oas.org/juridico/pdfs/mesicic4_ecu_const.pdf. Acesso em: 17 jun. 2019.

FERRARESI, Eurico. Ação popular, ação civil pública e mandado de segurança coletivo: instrumentos processuais coletivos. 1. ed. Rio de Janeiro: Forense, 2009.

FERREIRA, Marilene Aparecida. Pacha Mama: os direitos da natureza e o novo constitucionalismo na América Latina. Revista de Direito Brasileira. São Paulo, v. 4, n. 3, p. 400-423, jan./abr. 2013. Disponível em: https://www.indexlaw.org/index.php/rdb/ article/view/2644/2538. Acesso em: 12 ago. 2019.

GARZÓN, Rene Patricio Bedón. Aplicación de los Derechos de la Naturaleza en Ecuador. Revista Veredas do Direito. Belo Horizonte, v. 14, n. 28, p. 13-32, jan./abr. 2017. Disponível em: http://www.domhelder.edu.br/revista/index.php/veredas/article/ view/1038/537. Acesso em: 9 maio 2019.

GOMES, Ariel Koch. Natureza, Direito e homem: sobre o fundamento do Direito ao Meio Ambiente. Porto Alegre: Livraria do Advogado Editora, 2013.

GUAMÁN, Adoración; APARÍCIO, Marco. Los derechos de la Naturaleza y la lucha frente al poder corporativo em Ecuador. El caso Texaco-Chevron, los alcances del ecoconstitucionalismo y las deficiencias de los mecanismos de garantía y reparación. In: ACHURY, Liliana Estupiñana et al. La naturaleza como sujeto de derechos en el constitucionalismo democrático. Bogotá: Universidad Libre, 2019.

JAPIASSÚ, Hilton; MARCONDES, Danilo. Dicionário básico de filosofia. 5. ed. Rio de Janeiro: Jorge Zahar, 2008.

LEITE, José Rubens Morato. Manual de direito ambiental. São Paulo: Saraiva, 2015.

MALERBA, Juliana. A luta por justiça socioambiental na agenda feminista: visibilizando alternativas e fortalecendo resistências. In: ARANTES, Rivane; GUEDES, Vera (org.). Mulheres, trabalho e justiça socioambiental. Recife: SOS Corpo, 2010. Disponível em: http://209.177.156.169/libreria_cm/archivos/pdf_953.pdf\#page=13. Acesso em: 24 ago. 2020.

MILARÉ, Édis. Direito do Ambiente. 9. ed. São Paulo: Revista dos Tribunais, 2014.

NOVA ZELÂNDIA. Te Ureara. [2014]. Disponível em: http://www.legislation.govt.nz/act/public/2014/0051/latest/DLM6183601. html. Acesso em: 24 maio 2020.

NOVA ZELÂNDIA. Te Awa Tupua (Whanganui River Claims Settlement). [2017]. Disponível em: http://www.legislation.govt.nz/ act/public/2017/0007/latest/whole.html. Acesso em: 24 maio 2020.

NUNES, Dierle. Processo jurisdicional democrático: uma análise crítica das reformas processuais. Curitiba: Juruá, 2012.

OLIVEIRA, Fábio Corrêa Souza de. Direitos da natureza: biocentrismo? In: Direito e Desenvolvimento, v. 8, n. $2,2017$.

PORTO-GONÇALVES, Carlos Walter. A globalização a natureza e a natureza da globalização. Rio de Janeiro: Civilização Brasileira, 2015.

PASTOR, Roberto Viciano. La problemática constitucional del reconocimiento de la Naturaleza como sujeto de derechos en la Constitución del Ecuador. In: ACHURY, Liliana Estupiñana et al. La Naturaleza como sujeto de derechos en el constitucionalismo democrático. Bogotá: Universidad Libre, 2019.

RIBEIRO, Wagner Costa. Justiça espacial e justiça socioambiental: uma primeira aproximação. The Scientific Electronic Library Online - SciELO, São Paulo, v. 31, n. 89, jan./abr. 2017. Disponível em: https://www.scielo.br/scielo.php?script=sci_arttext\&pi$\mathrm{d}=$ S0103-40142017000100147\#aff1. Acesso em: 24 ago. 2020.

SANTOS, Boaventura de Sousa. Direitos Humanos, democracia e desenvolvimento. In: SANTOS, Boaventura de Sousa; MARTINS, Bruno Sena (org.). O pluriverso dos Direitos Humanos: a diversidade das lutas pela dignidade. 1. ed. Belo Horizonte: Autêntica Editora, 2019. 
SANTOS, Boaventura de Sousa. Para uma revolução democrática da justiça. 3. ed. ver. e ampl. Coimbra: Almedina, 2014.

SANTOS, Karinne Emanoela Goettems dos. Processo civil e litigiosidade: para além da jurisdição dos conceitos sem coisas. Rio de Janeiro: Lumen Juris, 2016.

SASS, Liz Beatriz. Direito e Natureza, (re)construindo vínculos a partir de uma ecocidadania. Curitiba: Juruá Editora, 2008.

WATANABE, Kazuo. Acesso à ordem jurídica justa (conceitos atualizados de acesso à justiça) processos coletivos e outros estudos. Belo Horizonte: Del Rey, 2019. 